\title{
Sensory and antioxidant evaluation of functional drinks based on Cardamom rhizomes (Amomum cardamomum willd.)
}

\author{
1,* Winarsi, H., ${ }^{1}$ Nuraeni, I., ${ }^{2}$ Roselina, A. and ${ }^{2}$ Andreas, A. \\ ${ }^{1}$ Department of Nutrition Science, Faculty of Health Sciences, Universitas Jenderal Soedirman, Purwokerto, \\ 53123, Central Java, Indonesia \\ ${ }^{2}$ Sinar Kasih Hospital, Purwokerto, Indonesia
}

Article history:

Received: 4 June 2020

Received in revised form: 16 July 2020

Accepted: 9 August 2020

Available Online: 22

September 2020

Keywords:

Functional drink,

Cardamom rhizome,

Sensory,

Phenolic,

Antioxidants

DOI:

https://doi.org/10.26656/fr.2017.4(6).265

\begin{abstract}
The study aimed to obtain a functional drink formula from the cardamom rhizomes (FdCarrhi) in terms of total phenol content and its vitamin C. A total of five formulations of drinks containing cardamom rhizomes and other spices have been made by boiling all ingredients and leaving excess liquid reaching 30-35\%. Sensory tests performed include color, taste, flavor, spiciness, aftertaste, and warm sensation. The panelists consisted of 55 people who were not trained, on a 1-5 hedonic scale; dislike extremely to like extremely. The total phenol, vitamin $\mathrm{C}$, protein, fat, ash, water and carbohydrates of the preferred formula have been determined. The selected formula drink composed of $2.12 \%$ cardamom rhizomes, various spices, and water. The color, taste, flavor, spiciness, and aftertaste ranged from like-moderately to like-extremely, while warm-sensation ranged from neutral to like-moderately. The content of total phenols was $498.8 \mathrm{ppm}$ and vitamin $\mathrm{C}$ is 36 $\mathrm{mg} / 100 \mathrm{~g}$. Fd-Carrhi rich in antioxidants.
\end{abstract}

\section{Introduction}

The high incidence of degenerative diseases encourages people to take an effort of prevention. Several studies have reported that the emergence of degenerative diseases is due to the accumulation of free radicals in the body (Chatterjee et al., 2007). One of the substances which can control the work of free radicals is antioxidants. As a consequence, there are many beverages products based on rhizomes with rich antioxidants in the market such as turmeric-tamarind, ginger, Curcuma, beverages, and others. These products are known as herb beverages which are believed to have the capability to improve health, but unfortunately still less supported by scientific evidence.

Winarsi et al. (2012) stated that every part of Cardamom (Amomum cardamomum Willd.) contains bioactive compounds. That statement was supported by the finding of Winarsi et al. (2016a) that extract cardamom rhizome contains $324.51 \mathrm{mg} / \mathrm{g}$ flavonoids, $0.73 \mathrm{mg} / \mathrm{g}$ vitamin $\mathrm{C}$, and $0.22 \mathrm{~mL} / \mathrm{g}$ the essential oil, which has a higher level than in the leaves and stems cardamom. According to Winarsi et al. (2014a), Cardamom leaves contains flavonoids as amount 129 $\mathrm{mg} / \mathrm{g}$ and have been formulated as functional drinks. It is believed can improve antioxidant status, lipid profile, and immune status for people with diabetes. Flavonoids are potent antioxidant compounds, which are widely isolated from various plants (Agati et al., 2012). Winarsi et al. (2014a) also stated that besides has phenolic compounds, cardamom rhizome also contains vitamin C. Padayatty et al. (2003) stated that vitamin C is also an antioxidant compound. Winarsi et al. (2014a) also mentioned that the cardamom rhizome has proven to erode levels of LDL-ox and lower the total cholesterol in atherosclerosis rats, even could improve antioxidant and immune status (Winarsi et al., 2016b).

Based on these findings, cardamom rhizomes have potential as the ingredient of functional drinks that are beneficial for health. However, until now, there is no formula of beverages based on cardamom rhizomes which favored by many people as a healthy drink.

The problem is how cardamom rhizomes can be formulated as a functional drink that can be accepted by the public? This research was aimed to create a formula functional drink based on the cardamom rhizome and to know the content of total phenols and vitamin $\mathrm{C}$ of this product. 


\section{Materials and methods}

\subsection{Preparation of the cardamom chip rhizome (CCR)}

The cardamom rhizome was obtained from cardamom farmers in the village of Sumbang, Banyumas, Central Java, Indonesia. The cardamom rhizomes were cleaned, sliced thinly and dried using the cabinet dryer at the temperature of $57^{\circ} \mathrm{C}$ to dry (can be broken), and it called cardamom chip rhizome (CCR). The CCR was stored in plastic boxes with tight lids, until the production of formula drinks (Winarsi et al., 2015 with modifications).

\subsection{Preparation cardamom rhizome (Fd-Carrhi) drink}

The Fd-Carrhi was composed of a variety of CCR and added with spices such as wooden cup, cinnamon, cloves, star anise, ginger, lemongrass, lime leaves, a lowcalorie sweetener, and a little salt. The addition of extra spices is the adoption from the customs of the people in the city of Jogyakarta, Indonesia, who often drunk "wedang uwuh" that contain an assortment of spices. As well as cardamom seeds, cardamom rhizomes also have a spicy taste, off-flavor, slightly bitter and warm. Therefore, the addition of spices aims to improve the taste and flavor to be accepted by many people. Many spices added to the formula based on the findings of Winarsi et al. (2014b) with modification. The preparation of the Fd-Carrhi begins by creating a formula with a five proportion cardamom rhizome and spices as shown in Table 1.

Table 1. Proportion of cardamom chip rhizome (CCR) and spices

\begin{tabular}{lccccc}
\hline \multirow{2}{*}{ Component $(\mathrm{g})$} & \multicolumn{5}{c}{ Formula } \\
\cline { 2 - 6 } & $\mathrm{A}$ & $\mathrm{B}$ & $\mathrm{C}$ & $\mathrm{D}$ & $\mathrm{E}$ \\
\hline CCR & 5 & 7.5 & 10 & 12.5 & 15 \\
Wooden cup & 5 & 5 & 5 & 5 & 5 \\
Cinnamon & 2 & 2 & 2 & 2 & 2 \\
Cloves & 0.14 & 0.14 & 0.14 & 0.14 & 0.14 \\
Star anise & 2 & 2 & 2 & 2 & 2 \\
Ginger & 25 & 25 & 25 & 25 & 25 \\
Lemongrass & 7.63 & 7.63 & 7.63 & 7.63 & 7.63 \\
Tropicana slim & 2.5 & 2.5 & 2.5 & 2.5 & 2.5 \\
Lime leaves & 2 & 2 & 2 & 2 & 2 \\
Water (mL) & 500 & 500 & 500 & 500 & 500 \\
\hline
\end{tabular}

The production of beverages was conducted by preparing water $500 \mathrm{~mL}$, added with CCR, wooden cup, cinnamon, cloves, star anise, crushed ginger, and lemongrass until it boiled. Subsequently, keep it boiling with a small flame and stirred occasionally until the rest of the fluid up to $30-35 \%$, then it was filtered. Then, lime leaves were added into the product and continued to boil it again. After it was filtered, then liquid sweetener and a little salt were added as the final step of cardamom rhizome drink production.

\subsection{Sensory evaluation}

To determine the level of consumer acceptance, the sensory (hedonic test) of the Fd-Carrhi on its color, taste, flavor, spiciness, aftertaste, and warmness were tested. The hedonic test is a procedure to test the consumer acceptance of a product. A total of 55 people made up of employees and students of nutritional science at the agency authors, untrained (Lima et al., 2012) were selected as panelists. Panelists were asked to express their personal preference on the tested products and to show the level of like and dislike to the product with a hedonic scale. The tested attributes were color, taste, flavor, spiciness, aftertaste, and a warm sensation for five sample drinks (A, B, C, D, and E). Hedonic scale which used was1-5, where the $1=$ strongly dislike (dislike extremely), $2=$ not like (dislike moderately), $3=$ ordinary (neutral), $4=$ likes (like moderately), $5=$ very like (like extremely). The number of panelists used as replication.

Technically, the panelists came to the table which provides the tested drinks one by one. Samples were presented at the same time with random order. The samples were coded using a 3-digit number. Panelists were asked to give the rate of each sample by giving a tick $(\sqrt{ })$ in the form provided. Each time the panelists completed the assessment of the samples, they were asked to neutralize the taste by drinking water, and stopped about $10 \mathrm{~s}$, then move on to the next samples. The sensory test was conducted between 08:00 to 11:30 a.m., with fluorescent lighting (white). The tested samples were presented in cold conditions at a temperature of $5^{\circ} \mathrm{C}$ in a transparent glass cup. To verify the acceptance of the tested drinks, as well as to standardize and to evaluate each of sensory attributes, so the amount of acceptable factor (AF) was determined according to Dutcosky (1996) based on the following formula:

$$
\mathrm{AF}=\mathrm{A} \cdot 100 . \mathrm{B}^{-1}
$$

Where $\mathrm{A}$ is the average value of each attribute and $\mathrm{B}$ is the average maximum value of each attribute.

The determination of the selected formula was based on the highest average value of all attributes. Afterwards, physicochemical characterization and proximate analysis were tested on the selected formula Fd-Carrhi.

\subsection{Determination of total phenol content}

The Folin-Ciocalteu method was used to determine the total phenols as described by (Singleton and Rossi, 1965). The estimation of total phenols in the product was carried out in triplicate. Tannic acid was used as a 
standard and the results obtained were expressed as $\mathrm{mg} / 100 \mathrm{~g}$ or ppm. For the standard curve, $10 \mathrm{mg}$ Tannic acid was weighed and dissolved in $100 \mathrm{~mL}$ ethanol $95 \%$, as the stock solution. Serial dilution of $0.02 \mathrm{mg} / \mathrm{mL}, 0.04$ $\mathrm{mg} / \mathrm{mL}, 0.06 \mathrm{mg} / \mathrm{mL}, 0.08 \mathrm{mg} / \mathrm{mL}$, and $0.10 \mathrm{mg} / \mathrm{mL}$ were made. An aliquot $(1 \mathrm{~mL})$ of each solution series was pipetted and added by $1.5 \mathrm{~mL}$ of Folin ciocalteau reagent $10 \%$, then leave it for 5 mins at room temperature. Then $1.5 \mathrm{~mL}$ of a solution of sodium bicarbonate $\left(\mathrm{NaHCO}_{3}\right) 0.556 \mathrm{M}$ was added, shake it until homogenous and stored in a dark room for 90 mins. The absorbance was read at a wavelength of $725 \mathrm{~nm}$. The regression equation was plotted as follow:

$$
\mathrm{y}=\mathrm{ax}+\mathrm{b}
$$

Where $\mathrm{y}$ is the absorbance; $\mathrm{x}$ is the concentration of the Tannic acid; $\mathrm{a}$ is the slope; and $\mathrm{b}$ is the intercept.

\subsection{Determination of vitamin C levels}

The vitamin $\mathrm{C}$ was determined using Iodine titration. The sample was weighed as an amount of $25 \mathrm{mg}$ then dissolved in $50 \mathrm{~mL}$ aquadest and $2 \mathrm{~mL}$ amylum $0.5 \%$. The titration was performed with a solution of iodine $\left(\mathrm{I}_{2}\right)$ until the blue color was formed. Levels of vitamin $\mathrm{C}$ were calculated by the formula:

$$
\text { Vitamin } \mathrm{C}=\frac{\left(\mathrm{NI}_{2} \times \mathrm{VI}_{2} \times \mathrm{BE} \text { vitamin } \mathrm{C}\right)}{\mathrm{W}_{\mathrm{sample}}} \times 100
$$

Where $\mathrm{NI}_{2}$ is the normality of Vitamin $\mathrm{C}(0.00945 \mathrm{~N})$, $\mathrm{VI}_{2}$ is the volume of iodine titration $(\mathrm{mL})$ and $\mathrm{W}_{\text {sample }}$ is the weight of titrated sample $(\mathrm{g})$

\subsection{Statistical analysis}

Data analysis was carried out by ANOVA, then the difference between the samples was determined by the Duncans Multiple Range Test (DMRT). Differences were considered significant at $P<0.05$.

\section{Results and discussion}

The cardamom chip rhizomes (CCR) were produced by washing the cardamom rhizome, sliced it around 0.5$1 \mathrm{~cm}$, and then dried using a dryer cabinet at a temperature of $57^{\circ} \mathrm{C}$. The CCR was stored in a plastic box until it is used. The scent of CCR was fresh, has a strong flavor, and chelate. The preparation of formula $\mathrm{Fd}$ -Carrhi refers to the formula drink based-cardamom leaf by Winarsi et al. (2014a) with slight modifications. Five formulas with varying amounts of rhizome chip cardamom have been made, so that the formula is acceptable and can be chosen by the panelists (Table 1). Each formula was added with $500 \mathrm{~mL}$ of water and boil it for a certain time. The longer the boiling time, the thicker the liquid will be, therefore in order to get the desired thickness to continue to boil with low heat, until the remaining liquid reached approximately $30-35 \%$. The result of this product was reddish-brown, and it seems there is no difference in each formula.

\subsection{Sensory properties}

The results of sensory tests include color, taste, flavor, spiciness, aftertaste, and a warm sensation caused as average values \pm SD and acceptability factors (AF) for all five formulas were presented in Table 2. The antioxidant levels of drink based on cardamom rhizome selected formula were described in Table 3.

\subsubsection{Color}

Color is a characteristic that determines the acceptance or rejection of a product by consumers. First impressions of customers from food and beverage products are color. Westland and Shin (2015) stated that the assessment of the quality of food material depends on several factors such as color, taste, texture, and nutritional value. However, the aspect of color more decisive than any other factors as mentioned above. The

Table 2. Sensory properties of the five formula drinks

\begin{tabular}{lccccc}
\hline \multirow{2}{*}{ Sensory } & \multicolumn{5}{c}{ Sample Code } \\
& $\mathrm{A}$ & $\mathrm{B}$ & $\mathrm{C}$ & $\mathrm{D}$ & $\mathrm{E}$ \\
\hline \multirow{2}{*}{ Colour } & $2.85 \pm 0.99^{\mathrm{b}}$ & $3 \pm 0.92^{\mathrm{b}}$ & $4.10 \pm 0.85^{\mathrm{a}}$ & $2.90 \pm 0.91^{\mathrm{b}}$ & $3.15 \pm 0.99^{\mathrm{b}}$ \\
& $(69.51)$ & $(73.17)$ & $(100)$ & $(70.73)$ & $(76.83)$ \\
Taste & $3.15 \pm 0.93^{\mathrm{b}}$ & $3.35 \pm 0.75^{\mathrm{b}}$ & $4.35 \pm 0.59^{\mathrm{a}}$ & $3.30 \pm 0.86^{\mathrm{b}}$ & $2.85 \pm 0.75^{\mathrm{b}}$ \\
& $(72.41)$ & $(77.01)$ & $(100)$ & $(75.86)$ & $(65.52)$ \\
Flavor & $3.40 \pm 0.82^{\mathrm{b}}$ & $3.65 \pm 0.81^{\mathrm{a}}$ & $4.0 \pm 0.65^{\mathrm{a}}$ & $3.65 \pm 0.89^{\mathrm{a}}$ & $2.80 \pm 0.52^{\mathrm{b}}$ \\
& $(85)$ & $(91.25)$ & $(100)$ & $(88.75)$ & $(70)$ \\
Spiciness & $3.5 \pm 0.89^{\mathrm{b}}$ & $3.75 \pm 0.91^{\mathrm{b}}$ & $4.30 \pm 0.8^{\mathrm{a}}$ & $3.8 \pm 0.81^{\mathrm{a}}$ & $2.85 \pm 0.75^{\mathrm{b}}$ \\
& $(81.4)$ & $(87.21)$ & $(100)$ & $(88.37)$ & $(66.28)$ \\
Aftertaste & $2.95 \pm 1^{\mathrm{b}}$ & $3.10 \pm 0.85^{\mathrm{b}}$ & $4.15 \pm 0.93^{\mathrm{a}}$ & $2.75 \pm 0.72^{\mathrm{b}}$ & $3.05 \pm 0.89^{\mathrm{b}}$ \\
& $(71.08)$ & $(74.7)$ & $(100)$ & $(66.27)$ & $(73.49)$ \\
Warm sensation & $3.05 \pm 0.89^{\mathrm{b}}$ & $3.3 \pm 1.03^{\mathrm{b}}$ & $3.2 \pm 0.89^{\mathrm{a}}$ & $3.15 \pm 0.88^{\mathrm{b}}$ & $4.25 \pm 0.91^{\mathrm{a}}$ \\
& $(71.76)$ & $(77.65)$ & $(75.29)$ & $(74.12)$ & $(100)$ \\
\hline
\end{tabular}

Values are expressed as mean $\pm \mathrm{SD}(\mathrm{AF}), \mathrm{N}=30$. Values with different superscript letters in the same column indicate significant difference at the $\alpha$ level 0.05. A, Formula containing $5 \mathrm{~g}$ cardamom chip rhizome (CCR); B, Formula containing $7.5 \mathrm{~g}$ CCR; C, Formula containing $10 \mathrm{~g}$ CCR; D, Formula containing 12.5 g CCR; E, Formula containing 15 g CCR. 
results of the sensory test assessment to color on FdCarrhi can be seen in Figure 1.

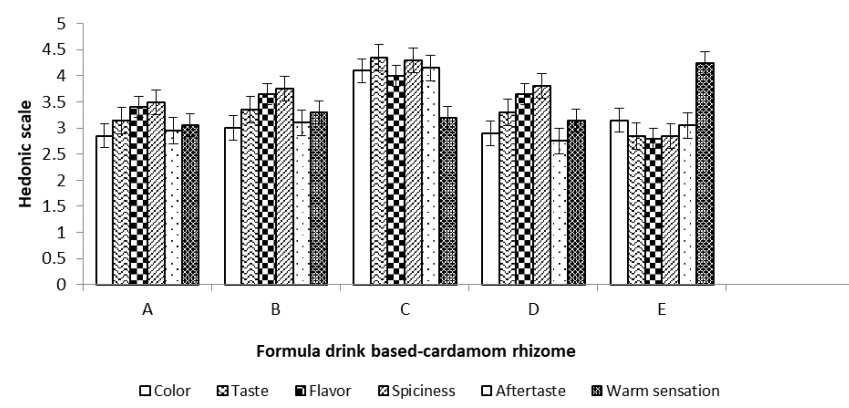

Figure 1. The results of the color, taste, flavor, spiciness, aftertaste, and a warm sensation of formula drink based on cardamom rhizomes. A, Formula containing $5 \mathrm{~g}$ cardamom chip rhizome (CCR); B, Formula containing 7.5 g CCR; C, Formula containing $10 \mathrm{~g} \mathrm{CCR}$; D, Formula containing 12,5 g CCR; E, Formula containing 15 g CCR.

The response of panelists based on acceptable factors to color on Fd-Carrhi, has shown that panelists prefer to the color of drink with code formula $\mathrm{C}$ with a value of $4.10 \pm 0.85$ (between like moderately and like extremely). The color of formula $\mathrm{C}$ is different from the other four formulas $(P<0.05)$, and it was selected as the preferred color formula.

\subsubsection{Taste}

The taste of the drink is a mixture of responses foretaste and flavor. The taste is influenced by several factors, such as chemical compounds, concentration, temperature, and interactions with other flavor components (Naknean and Meenune, 2010). The drink taste was produced from the mix of cardamom rhizomes and additional spices. Based on the preferred taste value of the panelists on Fd-Carrhi $(4.35 \pm 0.59)$ (like moderately to like extremely), it shows that formula $\mathrm{C}$ (Figure 1) has a different taste with other formulas $(P$ $<0.05)$. The addition of spices makes the taste of the drink more preferable to the panelist. However, the taste is not used as a parameter of functional food products, since the products which claimed as healthy drinks usually tasteless and a bit bitter.

\subsubsection{Flavor}

The flavor is the smell generated by chemical stimulation, Shepherd (2006) wafted by the olfactory nerve, which is located in the nasal cavity when the food entered to the mouth (Shepherd). Results of the hedonic test assessment on Fd-Carrhi can be seen in Figure 1. The response of panelists on Fd-Carrhi's flavor showed that the highest preferable scent is formula $\mathrm{C}$ with a scale of $4.0 \pm 0.65$ (like moderately). Formula $C$ was not statistically significant with formula B and D $(P<0.05)$, but the formula $\mathrm{C}$ has the highest acceptable factors (100). In general, the flavor which accepted by the nose and brain is the mixture of four principal flavor which are fragrant, sour, rancid, and charred. The flavor of food/drink is one of the main determination of delicacy/ freshness of the food. The possibility of a volatile essential oil and water-soluble substances in the rhizome cardamom and spices which added in the formula caused the flavor more preferable to the panelists.

The existence of other spices such as cinnamon, ginger, and cloves also improves the taste and flavor of the product. Besides, the spice also serves to increase the storage duration of products by acting as an antimicrobial and antioxidant. Lime leaves are known to contain essential oils which can improve the flavor of the beverage product. The benefit of essential oils for health is diverse such as a medium for relaxation, stress management, conventional antibiotics against microbes such as bacteria, viruses, and fungi. In addition to its essential oil content, lime leaves also contain flavonoid antioxidant compounds whose levels depend on the age of the leaf. The older age of the leaves results in higher flavonoid antioxidant level (Devy et al., 2010). This study used old lime leaves to obtain a higher level of flavonoids.

\subsubsection{Spiciness}

The hedonic quality test was conducted on the spiciness of Fd-Carrhi. This product contains aromatic compounds and has a typical spicy taste. The compounds contained in cardamom seeds include saponins, flavonoids, polyphenols, and essential oils. The average ratings of panelists acceptance rate to the level of spiciness based beverages cardamom rhizome was $4.30 \pm$ 0.8 , between like moderately and like extremely, which was a formula $\mathrm{C}$ (Figure 1). The level of spiciness formula $\mathrm{C}$ has no difference with the formula $\mathrm{D}$ $(\mathrm{P}>0.05)$, but different from the formula A, B, and $\mathrm{E}$ ( $\mathrm{P}$ $<0.05)$. Cardamom seeds and rhizomes may contain essential oils mainly cineol, terpineol, and borneol, which is a compound class of terpenes (Maurya et al., 2013). All chemical constituents of essential oil is a mixture of compounds, such as cardamom oil, it contains five major components such as cineol, borneol, limonene, alpha-terpinil acetate, and alpha-terpinen. When decomposed, cineol smelled delicious but spicy or has fresh sensations such as eucalyptus oil, borneol camphor smell like mothballs, limonene fragrant like tangerines, alpha-terpinil acetate smelled of lime, whereas alpha terpinen citrus smelled like citrus. The mixture of the five components that make the distinctive flavor of cardamom. 


\subsubsection{Aftertaste}

Aftertaste is a residual flavor or taste that remains in the mouth after eating or drinking. The Fd-Carrhi has an aftertaste which preferred by the panelists. The values given by the panelists to attribute of aftertaste was $4.15 \pm 0.93$, between like moderately and like extremely, and the value of the AF of 100 for the formula C. The aftertaste formula of $\mathrm{C}$ was different with that formula $\mathrm{A}$, $\mathrm{B}, \mathrm{D}$, and $\mathrm{E}(\mathrm{P}<0.05)$. In general, cardamom rhizomes have taste and flavors which are less preferred, but the addition of spices in the drink allows the aftertaste more preferable. Essential oil is a component that gives special flavor, while the non-volatile oil is a component which gives a spicy and bitter taste.

\subsubsection{Warm sensation}

The Fd-Carrhi gives a warm sensation to the body. The highest value of warm sensation identified in the formula $E$ with a value of $4.25 \pm 0.91$ between like moderately and like extremely, and that has a value of AF 100. Statistically, the value of the formula $E$ was not different from formula $\mathrm{A}(\mathrm{P}>0.05)$ with a value of $3.2 \pm 0.89$. Therefore, based on warm sensation, formulas $\mathrm{E}$ or $\mathrm{C}$ were selected.

Determination of selected formula based on the highest average value of the of all attributes. Formula $\mathrm{C}$ was selected on color attribute because it has the highest score and the AF of 100. Based on the taste, formula $\mathrm{C}$ was also chosen with a score between like moderately and like extremely and the value of AF 100. Formula C also selected as preferable formula based on its flavor with scores above like moderately with an AF value of 100. Panelists tend to like formula $\mathrm{C}$ based on its spiciness because this formula showed the highest value and the AF score is 100. Again, formula $\mathrm{C}$ also showed as the most preferred formula based on the aftertaste with scores above like moderately and AF 100. The FdCarrhi also will cause a warm sensation in the body, and the preferable formula based on its are formula $\mathrm{E}$ and $\mathrm{C}$, with no significant difference. Overall, formula C (10 g rhizome cardamom) is the most preferred formula based on almost all tested attributes.

Based on the average value of sensory, the ranking of product acceptance from high to low level was formula $\mathrm{C}, \mathrm{B}, \mathrm{D}, \mathrm{A}$, and $\mathrm{E}$. While the ranking of quality from high to low is on the attributes of taste, spiciness, warm sensation, aftertaste, color, and flavor. Afterwards, the antioxidant level of the selected formula will be tested, and the results as shown in Table 3. The following plan is the selected formula will be developed as a functional drink product for health.

\subsection{Total phenol level}

The content of total phenols test was conducted by Follin-Ciocalteu method to see the ability to reduce phenol component. The standards used are tannic acids (Kumar et al., 2010). The content of total phenols in FdCarrhi was $498.8 \pm 0.01 \mathrm{ppm}$ tannic acid present in the formula with $10 \mathrm{~g} \mathrm{CCR}$ (Table 3). Levels of total phenol beverages are also higher than ginger drink (447.93 ppm) (Ibrahim et al., 2015), but lower than the drink based ginger rhizome $(2,270-2,736 \mathrm{ppm})$ and turmeric $(3,509$ 3,705 ppm) (Setyowati and Suryani, 2013). Antioxidant activity is usually following to total phenols, meaning that the higher the content of phenols in a material, the higher the antioxidant activity (Huang et al., 2005). Phenol compounds inhibit free radicals by donating protons and form a stable radical. The formation of a stable radical is because free electrons in the radical stabilized by electron delocalization in the presence of resonance on the aromatic ring.

Phenolic compounds act as an antioxidant because it can bind oxygen, so it is not available for oxidation processes. In addition, the phenolic compounds also can bind metal which capable to catalyze the oxidation reaction (Khatun et al., 2006). Thus, there is an association between total phenolic compounds or phenol with antioxidant activity. According to Hincapié et al. (2011), antioxidant activity which demonstrated with the activity of radical scavenger in the solvent extract cannot be predicted based on the total phenol content, but rather by the presence of various compounds and their interactions.

Determination of total phenols is the basis for testing the antioxidant activity, as many researchers reported that phenolic compounds prevent oxidation reactions (Pourmorad et al., 2006; Borges et al., 2010). When the content of phenolic compounds in Fd-Carrhi is high, the antioxidant activity is also high. Antioxidant activity test can be done in vitro and in vivo. In vitro test can be carried out by determining the levels of vitamin $\mathrm{C}$ and total phenol product, as was done in this study. In vivo test can be conducted by the intervention beverage products to the animal or human for a certain time, and the antioxidant activity enzymatic were tested in a sample of blood or urine, both enzymes SOD, Catalase, or GSH-PX (Winarsi et al., 2016b; Winarto, Sasongko and Purwanto, 2016). In the future, Fd-Carrhi product will be tested in patients with degenerative diseases associated with oxidative stress.

What needs to be understood that the polyphenol compounds are widely found in plants such as phenolic acids, flavonoids, and tannins. Based on a flavonoid cardamom rhizome, in $100 \mathrm{~mL}$ Fd-Carrhi was equivalent 
to $83 \mathrm{mg}$ of flavonoids cardamom rhizomes according to Winarsi et al. (2016a). Until now, there is no standard doses for flavonoids. Mean flavonoid intake of adults (18 to 64 years) in the European Union by country and region is $428 \pm 49 \mathrm{mg} / \mathrm{d}$ (Vogiatzoglou et al., 2015). These compounds have different biological activity depending on the origin and the parts of the plant, so the health effects are also diverse. Antioxidant potential in most plants is usually shown by the presence of polyphenolic compounds (Matkowski and Piotrowska, 2006).

Table 3. Antioxidant levels of drink based on cardamom rhizome

\begin{tabular}{lcc}
\hline \multicolumn{1}{c}{ Component } & Fd-Carrhi & Placebo \\
\hline Total phenols $(\mathrm{mg} / 100 \mathrm{~g})$ & $49.88 \pm 0.01$ & $42.23 \pm 0.02$ \\
Vitamin C $(\mathrm{mg} / 100 \mathrm{~g})$ & $36 \pm 0.01$ & $23 \pm 0.02$ \\
\hline
\end{tabular}

Fd-Carrhi, Formula drink based on cardamom rhizome

\subsection{Vitamin $C$}

The Fd-Carrhi besides rich of phenolic antioxidants are also rich in vitamin $\mathrm{C}$. The content of vitamin $\mathrm{C}$ in Fd-Carrhi product was $36 \mathrm{mg} / 100 \mathrm{~g}$ (Table 3). The content of vitamin $\mathrm{C}$ in that drink can meet the requirement of $41.33 \%$ RDA of vitamin $\mathrm{C}$ a day for women aged 50-64 year. Based on its physiological and biochemical characteristic, vitamin $\mathrm{C}$ is known for its action as an electron donor. Ascorbic acid donates two electrons of the carbon of the double bond between the second and third of six molecules of carbon. Vitamin $C$ is called an antioxidant by donating electrons (Adikwu and Deo, 2013). Vitamins are able to prevent the oxidation of other substances. When vitamin $\mathrm{C}$ donates its electrons, it loses its electron sequentially. By losing one electron, the semidehydroascorbic or ascorbyl acid radical compounds are formed. Compared with other free radicals, ascorbyl radical is relatively stable and fairly active with a part-time $10^{5}$ seconds. Based on the content of vitamin $\mathrm{C}$, the Fd-Carrhi included a drink which rich in antioxidants that are good for health.

The formula drinks based on cardamom rhizomes comprises of $2.12 \%$ cardamom rhizomes chip, $1.06 \%$ wooden cup, $0.42 \%$ cinnamon, $0.03 \%$ cloves, $0.42 \%$ star anise, $5.29 \%$ ginger, $1.61 \%$ lemongrass, $0.31 \%$ low calorie sugar, $0.06 \%$ salt, $0.44 \%$ lime leaves, and $88.23 \%$ water. That formula has a score between like moderately and like extremely for the attributes of color, taste, flavor, spiciness, and aftertaste, while the warm sensation score neutral to like moderately. The total phenols content was $498.8 \mathrm{ppm}$, while the vitamin $\mathrm{C}$ was $36 \mathrm{mg} / 100 \mathrm{~g}$. That Fd-Carrhi is adequate for the need of $41.33 \%$ RDA of vitamin $C$ for women with 50-64 years aged. In $100 \mathrm{~mL}$ of Fd-Carrhi product contains flavonoids equivalent to $83 \mathrm{mg}$, are suitable for therapeutic purposes health. Thus, drink basedcardamom rhizome is rich in antioxidants. Possibility, that are beneficial for preventing the development of degenerative diseases, it needs to be proven in future studies.

\section{Conflict of Interest}

The authors declare no conflict of interest.

\section{Acknowledgments}

We gratefully thank the Director General of the Ministry of Research, Technology and Higher Education for funding this research-based Competence Grant, 2017 budget.

\section{References}

Adikwu, E. and Deo, O. (2013). Hepatoprotective effect of vitamin $\mathrm{C}$ (Ascorbic Acid). Journal Pharmacy and Pharmacology, 4, 84-92. https:// doi.org/10.4236/pp.2013.41012

Agati, G., Azzarello, E., Pollastri, S. and Tattini, M. (2012). Flavonoids as antioxidants in plants: location and functional significance. Plant Science, 196, 6776. https://doi.org/10.1016/j.plantsci.2012.07.014

Borges, G., Mullen, W. and Crozier, A. (2010). Comparison of the polyphenolic composition and antioxidant activity of European commercial fruit juices. Food and Function, 1(1), 73-83. https:// doi.org/10.1039/c0fo00008f

Chatterjee, M., Saluja, R., Kanneganti, S., Chinta, S. and Dikshit, M. (2007). Biochemical and molecular evaluation of neutrophil NOS in spontaneously hypertensive rats. Cellular and Molecular Biology (Noisy-le-Grand, France), 53(1), 84-93.

Devy, N.F., Yulianti, F. and Andrini. (2010). The content of flavonoids and limonoids on the different phase growth Kalamondin Citrus (Citrus mitis Blanco) and lime (Citrus hystrix DC.). Jurnal Hortikultura, 20 (1), 360-367.

Dutcosky, S.D. (1996). Sensory analysis of food. Curitiba, Brasil: Champagnat.

Hincapié, C.A., Monsalve, Z., Seigler, D.S., Alarcón, J. and Cespedes, C.L. (2011). Antioxidant activity of Blechnum chilense (Kaulf.) Mett., Curcuma domestica Valeton and Tagetes verticillata Lag. and Rodriguez. Boletín Latinoamericano y del Caribe de Plantas Medicinales y Aromáticas, 10(4), 315-324.

Huang, D., Ou, B. and Prior, R.L. (2005). The chemistry behind antioxidant capacity assays. Journal of Agricultural and Food Chemistry, 53, 1841-1856. https://doi.org/10.1021/jf030723c 
Ibrahim, A.M., Yunianta. and Srihertyna, F.H. (2015). The influence of the temperature and the length of time the extraction of the chemical and physical properties in the manufacture of juice drinks red ginger (Zingiber officinale var. Rubrum) in combination with the addition of honey as a sweetener. Jurnal Pangan dan Agroindustri, 2(3), 530-541.

Khatun, M., Eguchi, S., Yamaguchi, T., Takamura, H. and Matoba, T. (2006). Effect of thermal treatment on radical scavenging activity of some spices. Food Science and Technology Research, 12(3), 178-185. https://doi.org/10.3136/fstr.12.178

Kumar, D., Viberg, J., Nilsson, A.K. and Chabes, A. (2010). Highly mutagenic and severely imbalanced dNTP pools can escape detection by the S-phase checkpoint. Nucleic Acids Research, 38(12), 39753983. https://doi.org/10.1093/nar/gkq128

Lima, I.F.P., De Dea Lindner, J., Soccol, V.T., Parada, J.L. and Soccol, C.R. (2012). Development of an innovative nutraceutical fermented beverage from herbal mate (Ilex paraguariensis A.St.-Hil.) extract. International Journal of Molecular Sciences, 13(1), 788-800. https://doi.org/10.3390/ijms13010788

Matkowski, A. and Piotrowska, M. (2006). Antioxidant and free radical scavenging activities of some medicinal plants from the Lamiaceae. Fitoterapia, 77(5), 346-353. https://doi.org/10.1016/ j.fitote.2006.04.004

Maurya, S., Kushwaha, A.K. and Singh, G. (2013). Biological significance of spicy essential oils. Advances in Natural Science, 6(4), 84-95.

Naknean, P. and Meenune, M. (2010). Factors affecting retention and release of flavor compounds in food carbohydrates. International Food Research Journal, 17, 23-34.

Padayatty, S.J., Katz, A., Wang, Y., Eck, P., Kwon, O., Lee, J-H., Chen, S., Corpe, Ch., Dutta, A., Dutta, S.K. and Levine, M. (2003). Vitamin C as an antioxidant: evaluation of its role in disease prevention. Journal of the American College of Nutrition, 22(1), 18-35. https:// doi.org/10.1080/07315724.2003.10719272

Pourmorad, F., Hosseinimehr, S.J. and Shahabimajd, N. (2006). Antioxidant activity, phenol and flavonoid contents of some selected Iranian medicinal plants. African Journal of Biotechnology, 5(11), 1142-1145.

Setyowati, A. and Suryani, C.L. (2013). Increased levels of antioxidant activity of curcumin and instant drinks ginger and turmeric. Agritech, 33(4), 363-370.

Shepherd, G.M. (2006). Smell images and the flavor system in the human brain. Nature, 444, 316-321. https://doi.org/10.1038/nature05405

Singleton, V.L. and Rossi, J.A. (1965). Colorimetry of total phenolics with phosphomolybdic acidphosphotungstic acid reagents. American Journal of Enology and Viticulture, 16, 144-158.

Vogiatzoglou, A., Mulligan, A.A., Lentjes, M.A.H., Luben, R.N., Spencer, J.P.E., Schroeter, H., Khaw, K-T. and Kuhnle, G.G.C. (2015). Flavonoid intake in European adults (18 to 64 Years). Plos One, 10(5), 1 -22. https://doi.org/10.1371/journal.pone.0128132

Westland, S. and Shin, M.J. (2015). The relationship between consumer colour preferences and productcolour choices. Journal of the International Colour Association, 14, 47-56.

Winarsi, H., Sasongko, N.D. and Purwanto, A. (2016). Germinated-soy milk in suppressing inflammation and oxidative stress in blood plasma and breast milk of lactating mothers. International Food Research Journal, 23(2), 646-652.

Winarsi, H., Sasongko, N.D., Purwanto, A., Arinton, I.G. and Nuraeni, I. (2012). In vitro antioxidant activity of the stem and leaves Amomum cardamomum extracts. Paper presented at the International Conference on Medicinal Plants, October 11-12. Universitas Jenderal Soedirman, Purwokerto, Indonesia.

Winarsi, H., Sasongko, N.D., Purwanto, A. and Nuraeni, I. (2014a). Effect of cardamom leaves extract as antidiabetic, weight lost and hypocholesterolemic to alloxan-induced Sprague Dawley diabetic rats. International Food Research Journal, 21(6), 22532261.

Winarsi, H., Sasongko, N.D., Purwanto, A. and Nuraeni, I. (2014b). Functional drinks rich in flavonoids cardamom leaves as antiatherogenic agent for women with type 2 diabetes mellitus. P00201407260. Indonesia: Director General of Intellectual Property.

Winarsi, H., Yuniaty, A. and Nuraeni, I. (2015). Extract cardamom rhizome (Amomum Cardomomum) rich in flavonoids as antioxidants, immunostimulant, and antiatherosclerotic. P00201508144. Indonesia: Director General of Intellectual Property.

Winarsi, H., Yuniaty, A. and Nuraeni, I. (2016a). Hypocholesterolemic and attenuated oxidized-LDL of epinephrine-induced atherosclerosis rats using cardamom rhizome ethanolic extract: Study of functional-food components. International Food Research Journal, 23(5), 2116-2124.

Winarsi, H., Yuniaty, A. and Nuraeni, I. (2016b). Improvement of antioxidant and immune status of atherosclerotic rats adrenaline and egg-yolks induced using cardamom-rhizome ethanolic extract: an initial study of functional food. Agriculture and Agricultural Science Procedia, 9, 264-270. https:// doi.org/10.1016/j.aaspro.2016.02.147 